\title{
Investigation of Tooth Wear and its Associated Etiologies in Adult Patients Visiting Dental Institute in India
}

\section{Saee Deshpande*}

Department of Prosthodontics, VSPM's Dental College and Hospital, Nagpur, India

\begin{abstract}
Aim: To evaluate the prevalence, severity and patient's awareness of tooth wear in adults visiting VSPMDCRC Nagpur.

Methodology: A cross-sectional study was designed. The sample size was determined by using single proportion formula. A validated questionnaire was used to evaluate prevalence, grade of severity of tooth wear. Other factors such as presence of dentinal sensitivity and habits were also included. A total of 570 patients were examined, both male and females of age group 25-55 years with periodontally sound dentition were included in the study.

Results: Chi-square test for linear trend was applied for statistical analysis. Total 570 patients were investigated out of which $245(43 \%)$ patients showed signs of tooth wear. Prevalence of tooth wear was $45 \%$ for males and $41 \%$ for females. Prevalence of tooth wear and its severity increased with advancing age. $38 \%$ of patients with tooth wear complained of dentinal hypersensitivity. Majority of patients $55 \%$ who had tooth wear reported habit of chewing of tobacco related products. Patients with tooth wear of grade 1 and 2 showed lack of awareness of their condition however those with grade 3 showed increased awareness (35\%) and it doubled as the grade progressed to 4 .
\end{abstract}

Conclusion: Tooth wear is a prevalent condition in this population. The severity increased as the age progressed. Tobacco chewing is also prevalent in patients showing tooth wear. There was lack of awareness in patients showing initial tooth wear however as the wear progressed $74 \%$ of patients sought the treatment.

Clinical Significance: The implication for dentists is that efforts should be made to increase the awareness about tooth wear. Also, early diagnosis and prevention are vital to the well being of the patients.

Keywords: Tooth wear; Dentinal hypersensitivity; Oral habit

\section{Introduction}

Tooth wear is a universal consequence of aging [1]. The cause of pathological levels of tooth wear is difficult to diagnose and is generally a result of abrasion, attrition, and erosion [2]. It is therefore difficult to select specific etiologies and make assumptions based on theories that assume that they do not co-exist with each other.

There has been increasing interest in tooth wear in dental literature. While there is a decline in the prevalence of caries in industrialized countries, some authors describe a general trend of increasing tooth wear amongst the young. There is abundant data on prevalence of tooth wear in children and adolescents but data on adults is scanty and scattered. Anecdotal clinical experiences suggest tooth wear to be common in adults however little evidence exists on the natural course of the condition. The irreversible and multifactorial aspects of tooth wear process make it one of the most difficult problems to manage and early diagnosis of wear is important.

The only reliable way to measure changes to teeth in large populations are tooth wear indices [3]. Most indices use changes to the anatomical appearance of teeth to record the amount of wear. Some indices measure tooth wear on every surface of every tooth, some use selected sites and others use specific surfaces. The difficulty lies in making a diagnosis of the etiology and then using an index which does not record other causes of tooth wear. Most importantly, it is clinically very challenging to diagnose the etiology from the appearance of a lesion without a comprehensive dietary and dental history [4]. In most cases changes to the anatomy of teeth from tooth wear is a combination of erosion, abrasion and attrition and it is difficult to assess which component is most important. It is generally safer not to be specific and use an index to record change and then use the results to allow analysis of risk factors to identify the cause. The ordinal scale used in the present study was used byJohanson. Its intra-examiner and inter- examiner reproducibility have been shown to be approximately $90 \%$ and it is also easy to use 4 .

Hence, present study was planned with following aim and objectives

\section{Objectives}

- To investigate the association between tooth wear, its severity and age and gender

- To investigate association between tooth wear severity, presence of habits (tobacco chewing) and awareness of condition amongst study subjects.

\section{Materials and Methods}

This is a cross-sectional study conducted on adult patients visiting VSPM's Dental College during the period of July-December 2011. The sample size of the study was determined using single proportion formula. Written consent of the patients was obtained. The exclusion criterion was patients' unwillingness to participate.

Ethical approval was obtained from Institutional Ethics Committee VSPM's Academy of Higher Education.

*Corresponding author: Saee Deshpande, PhD, Department of Prosthodontics, VSPM's Dental College and Hospital, Nagpur, Maharashtra, India, Tel: +91 9225213204; E-mail: drsaeedeshmukh@gmail.com

Received August 11, 2014; Accepted December 08, 2014; Published December 12, 2014

Citation: Deshpande S (2015) Investigation of Tooth Wear and its Associated Etiologies in Adult Patients Visiting Dental Institute in India. Dentistry 5: 271 doi:10.4172/2161-1122.1000271

Copyright: ( 2015 Deshpande S. This is an open-access article distributed under the terms of the Creative Commons Attribution License, which permits unrestricted use, distribution, and reproduction in any medium, provided the original author and source are credited. 
A questionnaire incorporating the ordinal scale (Table 1) was designed to evaluate prevalence, grade of severity of tooth wear. Other factors such as presence of dentinal sensitivity, habits, diet, and tooth brushing technique were also included. Questionnaire was validated by 15 dentists.

\section{Questionnaire}

Name:

Age/sex:

Address:

Occupation:

Chief complaint:

Parafunctional habits:

Stress status: Mild/Moderate/Severe

Diet: 1. Beverages: Cold drinks/Hot drinks

Frequency:

\section{Veg./ Non veg}

Systemic diseases:

Brushing technique: toothbrush/ toothpaste/ tooth powder/ others Habits: pan/ tobacco/ betel nut/ khaini/ gutkha/ nail biting etc.

Intraoral Examination:

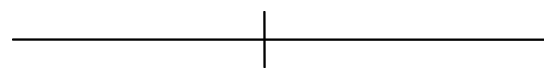

Periodontal status:

Occlusion:

Wear:

Extraoral: facial signs of vertical loss

TMJ: clicking/ pain/ deviation/ dysfunction $\mathrm{Y} / \mathrm{N}$

Patient's awareness of condition (wear)- whether seeks treatment?

Clinical oral examination of study subjects was done in the outpatient dental clinic using a disposable mouth mirrors and dental probes under the operating light on the dental chair unit. One expert dentist examined all the patients. All examinations were carried out by the operator in front of the subjects and the assistant seated behind to record the findings. Restored or carious tooth surfaces were excluded from the analysis.

Scores from 0-4 were given according to the severity of occlusal tooth wear.

A clear history of possible etiological factors such as parafunctional habits, oral hygiene methods, dietary habits and medical history was recorded.

SS version 12.0 statistical software was used (SPSS Incorporation Chicago, 2003) for data entry and analysis, and the results were expressed as frequencies and percentages.

\section{Results}

Total 570 patients were investigated out of which 245 (43\%) patients showed signs of tooth wear. Mean age for the study subjects was $39(\mathrm{SD} \pm 7)$ years. 293 patients were males and 277 were females.
All the observations are given in Tables 2-8.

Statistical analysis was carried out by applying chi-square test for linear trend.

1. Tooth wear and gender (Table 2): Prevalence of tooth wear was $45 \%$ for males and $41 \%$ for females. The difference in gender was not statistically significant $(\mathrm{p}=0.39)$.

2. Tooth wear and age (Table 3, Graph 1): Prevalence of tooth

\section{Grade Degree of occlusal wear}

0 No visible facets in enamel: Occlusal/Incisal morphology intact

1 Marked wear facets in enamel: Occlusal/Incisal morphology altered Wear into dentin: dentin exposed occlusally/incisally and/or adjacent

2 tooth surface: occlusal/incisal morphology changed in shape with height reduction of tooth

Extensive wear into dentin: larger dentin area $\left(>2 \mathrm{~mm}^{2}\right)$ exposed

occlusally/incisally and/or adjacent tooth surface; occlusal/incisal morphology totally lost locally or generally; substantial loos of crown height

$4 \quad$ Wear into secondary dentin (verified by photographs)

Note: $\sqrt{ }$ the grade that is applicable

Table 1: Ordinal scale used for grading severity of occlusal wear.

\begin{tabular}{|c|c|c|c|}
\hline Sex & Total & With tooth wear & $\%$ \\
\hline Males & 293 & 131 & 45 \\
\hline Females & 277 & 114 & 41 \\
\hline
\end{tabular}

Table 2: Prevalence of tooth wear in males and females.

\begin{tabular}{|c|c|c|c|}
\hline Age Group (yrs) & $\begin{array}{c}\text { Total patients } \\
\text { examined }\end{array}$ & Patients with tooth wear & $\%$ \\
\hline $\mathbf{1 8 - 2 9}$ & 189 & 43 & 23 \\
\hline $\mathbf{3 0 - 4 4}$ & 191 & 90 & 47 \\
\hline $\mathbf{4 5 - 5 5}$ & 190 & 92 & 48 \\
\hline
\end{tabular}

Table 3: Prevalence of tooth wear in different age groups.

\begin{tabular}{|c|c|c|}
\hline Wear grade & Total no of patients & $\%$ \\
\hline 1 & 71 & 29 \\
\hline 2 & 65 & 26 \\
\hline 3 & 59 & 24 \\
\hline 4 & 50 & 20 \\
\hline
\end{tabular}

Table 4: Prevalence of severity of tooth wear.

\begin{tabular}{|c|c|c|c|}
\hline Grades & $\mathbf{1 8 - 2 9}$ yrs & $\mathbf{3 0 - 4 4}$ yrs & $\mathbf{4 5 - 5 5}$ yrs \\
\hline 1 & 33 & 18 & 20 \\
\hline 2 & 27 & 31 & 7 \\
\hline 3 & 2 & 15 & 42 \\
\hline 4 & 0 & 16 & 34 \\
\hline
\end{tabular}

Table 5: Prevalence of tooth wear severity in different age groups.

\begin{tabular}{|c|c|c|}
\hline Grades & No. of patients & $\%$ \\
\hline $0-1$ & 51 & 54 \\
\hline 2 & 24 & 39 \\
\hline $3-4$ & 19 & 42 \\
\hline
\end{tabular}

Table 6: Prevalence of Dentinal hypersensitivity in patients with tooth wear.

\begin{tabular}{|c|c|c|}
\hline Grade & No of patients with habits & $\%$ \\
\hline 1 & 19 & 27 \\
\hline 2 & 37 & 57 \\
\hline 3 & 31 & 53 \\
\hline 4 & 37 & 74 \\
\hline
\end{tabular}

Table 7: Prevalence of habits in patients with tooth wear. 


\begin{tabular}{|c|c|c|}
\hline Grade & $\begin{array}{c}\text { No of patients who are aware of tooth wear } \\
\text { and seek treatment }\end{array}$ & $\%$ \\
\hline 1 & 0 & 0 \\
\hline 2 & 3 & 4 \\
\hline 3 & 21 & 36 \\
\hline 4 & 37 & 74 \\
\hline
\end{tabular}

Table 8: Patient's awareness of tooth wear

\section{Prevalence of tooth wear in different age groups}

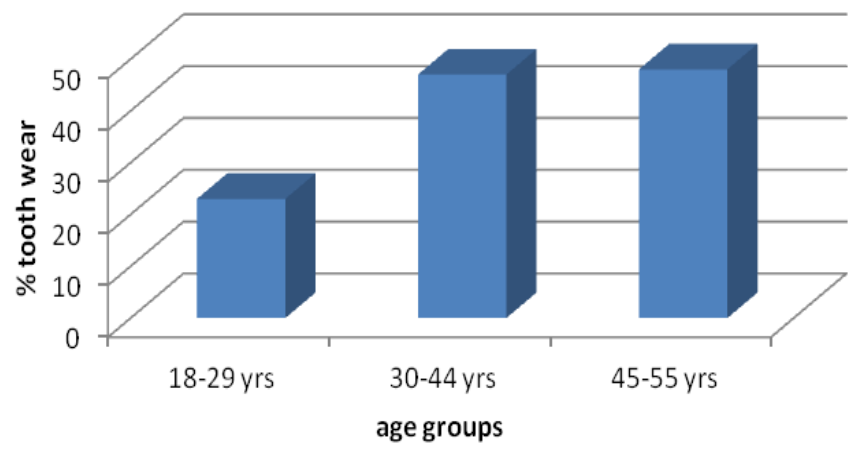

Graph 1: Prevalence of tooth wear in different age groups.

wear increased with advancing age. For the age group 30-44 years it was $47 \%$ and for $45-55$ years it was $48 \%$ as compared to $23 \%$ for $18-29$ years. The difference in age was statistically significant $(\mathrm{p}=0.0001)$

3. Severity of tooth wear and age (Tables 4, 5 and Graph 2): For the age groups 18-29 years grade 1 and 2 were most prevalent. For age groups 30-44 years grade 2 was most prevalent however grade 3 and 4 were also noted. For the age group 4555 years grade 3 was most prevalent. The difference in age was statistically significant ( $\mathrm{p}=0.0001)$.

4. Tooth wear and dentinal sensitivity (Table 6 and Graph 3): A total of 94 patients (38\%) with tooth wear complained of dentinal hypersensitivity. The difference was statistically significant $(\mathrm{p}=0.0001)$.

5. Tooth wear and Habits (Table 7 and Graph 4): A total of 134 (55\%) patients who had tooth wear reported habit of chewing of tobacco related products. The difference was statistically significant $(\mathrm{p}=0.0001)$.

6. Tooth wear and Awareness (Table 8): Patients with tooth wear of grade 1 and 2 showed lack of awareness of their condition however those with grade 3 showed increased awareness (35\%) and it doubled as the grade progressed to 4 . The difference was statistically significant $(\mathrm{p}=0.0001)$.

\section{Discussion}

Tooth wear is a common problem but most often left untreated. The prevalence figures suggest that tooth wear must be the fourth dimension risk factor for the aesthetics, function and longevity of the human dentition behind acute trauma, caries and periodontal disease [5-7]. Occlusal tooth wear in particular leads to loss of vertical dimension, poor masticatory efficiency and in most cases requires full mouth rehabilitation by extensive restorations.
Tooth wear is a composite term introduced to cover non-carious tooth surface loss by attrition, abrasion and erosion $[2,8]$. Both clinical and experimental observations showed that individual tooth wear type rarely exist alone but interact with each other[9].

\section{Severity of tooth wear in different}

\section{age groups}

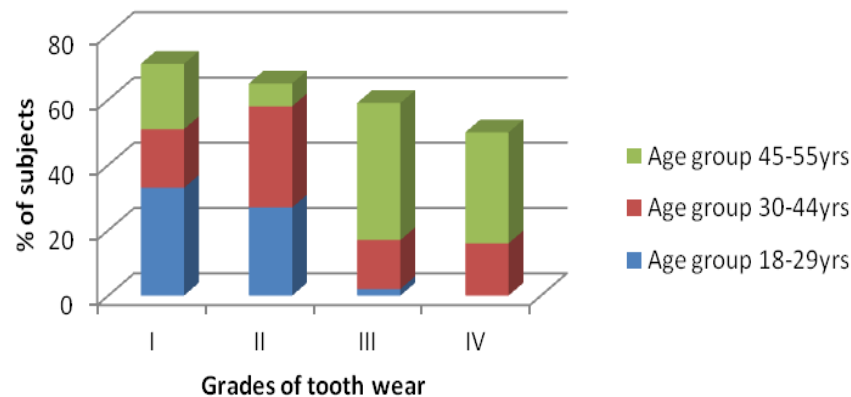

Graph 2: Severity of tooth wear in different age groups.

\section{Prevalence of habits in patients with tooth wear}

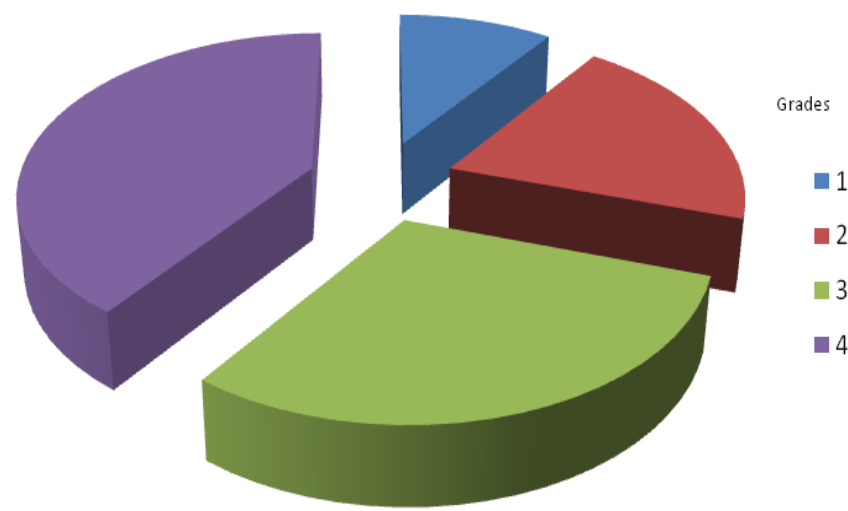

Graph 3: Prevalence of tobacco chewing habit in patients as related to severity of tooth wear (in \%).

Prevalence of Dentinal hypersensitivity in patients with tooth wear

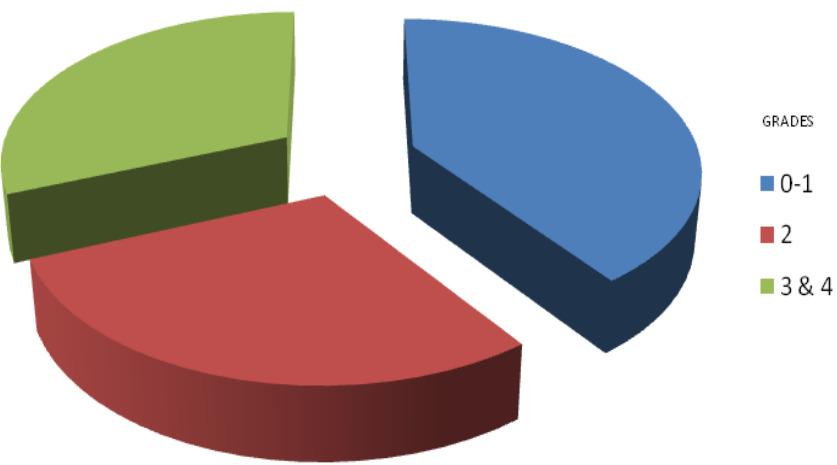

Graph 4: Prevalence of dentinal hypersensitivity in patients as related to severity of tooth wear (in \%). 
Tooth wear prevalence varies around the globe. Many researchers have studied the prevalence in many countries but the evidence in Indian population is scanty. A study in Sabah [10] shows that out of 148 individuals examined, 95 have TW with moderate dentine exposure and 41 have severely worn dentition. Out of the 126 subjects with TW in a Nigeria study [11] 81 had attrition, 20 had abrasion, and 9 had erosion while the remaining 16 had combination of both attrition and abrasion. Other study that examined 155 subjects attending a university dental clinic in Trinidad, West Indies [12] found that $72 \%$ of them had tooth surface loss with the majority (52\%) exhibiting mild, $16 \%$ with moderate and $4 \%$ with severe tooth surface loss. They found that there is an association between tooth surface loss and age, gastro-esophageal reflux disease and certain dietary patterns.

The difference between genders in relation to tooth wear has been reported in a number of studies. Most studies have reported the incidence to be more common in males [13]. In the present study also, out of 570 patients examined $131(45 \%)$ patients were male and $114(41 \%)$ were female. It has been observed that patients are increasingly concerned about their appearance and generally wish to delay the ageing process and this include the impact upon teeth. There is reasonably strong evidence to suggest that tooth wear is an age related phenomenon and it is common. A recent review concluded there was an increasing trend towards increasing wear with age [14]. In this study TW was $47 \%$ for the age group of 30-44 years and for $45-55$ years it was $48 \%$ as compared to $23 \%$ for $18-29$ years. At the same time when we were examining the prevalence of severity of tooth wear, it was observed that, for the age groups 18-29 years grade 1 and 2 were most prevalent. For age groups 30-44 years grade 2 was most prevalent however grade 3 and 4 were also noted. For the age group 45-55 years grade 3 was most prevalent.

Tooth wear often brings discomfort and sensitivity especially during eating, drinking or tooth brushing. Dentinal hypersensitivity (DH) is a painful clinical condition that affects $8-57 \%$ of adult population and is associated with the dentin exposure to the oral environment $[15,16]$. Clinical studies and questionnaires on $\mathrm{DH}$ indicate a prevalence of 4-74\%. It mostly affects individuals at the end of their third decade of life causing patient most discomfort [17]. In the present study the prevalence of $(\mathrm{DH})$ has been carried out with respect to the Grade of TW, where it is observed that, a total of 94 patients (38\%) with tooth wear complained of DH. About 51 patients was in Grade 0-1, 24 patients was in Grade 2 and [18] patients were in Grade 4. Secondary dentin formation may be the associated reason to cause less DH in the Grade 3-4 has been expected.

Oral habits have been identified to play a significant role in TW19 oral habits are repetitive behaviour in the oral cavity that results in the loss of tooth structure and they include dietary habits, brushing technique, bruxism, parafunctional habits and regurgitation. Their effect is dependent on the nature, onset and duration of habits [19].

As in studies, elsewhere in India, tobacco was predominantly used in smokeless forms [20-21] and is very popular in rural areas and this habit has increased in recent times (WHO, 1997). It has been estimated that 96 million (52\%) Indians consume tobacco in smokeless forms. The use of 'gutkha' and 'pan masala' with tobacco is common modalities of tobacco use [22]. Despite the prohibition on smoking in public and a proposed ban on consuming 'gutkha', our state i.e. Maharashtra remains one of the largest consumer of tobacco in any form in the country. The Global Adult Tobacco Survey (GALT) report indicated the current prevalence of tobacco use in Maharashtra is
$31.4 \%$ in adults [23]. In the present study also 124 patients who showed the TW had the habit of tobacco chewing in different forms. Tobacco contains abrasive silica particles a result of fallout from airborne dust. When tobacco products containing abrasive silica are mixed with saliva and chewed, an abrasive paste is formed that over times can wear down the teeth. The number of pathologically worn surfaces increases with the simultaneous increase in the frequency and duration of chewing tobacco [22]. Although we have not asked about the frequency and duration of the habit in our study, but data have shown that Grade $4 \mathrm{TW}$ is seen in $74 \%$ of patients but Grade 2 is also seen in $57 \%$ in contrast to $27 \%$ and $53 \%$ and in Gradel and 2 tooth wear respectively.

The challenge facing the dental team is to raise patients' awareness of the problems associated with tooth wear. At an early stage of development, patients with tooth wear might not notice their problem, but some may be concerned with the aesthetic and appearance especially if anterior teeth are involved. Therefore in this study we also investigated if the patient's levels of awareness of tooth wear. It was found that only when the tooth wear was advanced to grade 3 and 4 the patients became aware of it and seeked treatment. Timely diagnosis and preventive care can limit the amount of tooth surface loss and thus creating awareness amongst general population regarding the ill effects of tooth wear is must.

\section{Conclusion}

There is reasonably strong evidence to suggest that tooth wear is an age related phenomenon associated with chewing of tobacco related products and it is common amongst the study population. The presence of dentinal hypersensitivity is found to be more common at initial stages of tooth wear. As the severity increases, patients become more and more about the condition and seek treatment.

\section{Clinical Significance}

The implication for dentists is that efforts should be made to increase the awareness about tooth wear as a pathological process is important. Also, early diagnosis and prevention are vital to the well being of the patients.

\section{Limitation of Study and Recommendations}

In this study, some biological factors such as saliva, tooth composition and structure, type of occlusion and behavioral factors were not considered. For tooth brushing methods employed by subjects, factors such as the vigorosity of the techniques should be measured.

Tooth wear is an accumulative lifetime process which is irreversible and multifactorial in nature. The clinical expression of dental wear largely depends on the strength, frequency and duration of exposure to the abrasive and erosive challenges that can be modified to a certain extent by those biological factors.

Further investigations and continuous follow-up of cases may allow the mapping of the relationship of biological factors with the occurrence of tooth wear.

\section{References}

1. Smith BG, Robb ND (1996) The prevalence of toothwear in 1007 dental patients. J Oral Rehabil 23: 232-239.

2. Smith BG, Knight JK (1984) A comparison of patterns of tooth wear with aetiological factors. Br Dent J 157: 16-19.

3. Bardsley PF (2008) The evolution of tooth wear indices. Clin Oral Investig 12 Suppl 1: S15-19. 
Citation: Deshpande S (2015) Investigation of Tooth Wear and its Associated Etiologies in Adult Patients Visiting Dental Institute in India. Dentistry 5: 271. doi:10.4172/2161-1122.1000271

4. Johansson A, Omar R (1994) Identification and management of tooth wear. Int J Prosthodont 7: 506-516.

5. O'Brien.Children's dental health in the United Kingdom1993. London Office of Population Censuses and Surveys London: HMSO:1994

6. Nunn JH (1996) Prevalence of dental erosion and the implications for oral health. Eur J Oral Sci 104: 156-161.

7. Nunn JH (2000) Prevalence and distribution of tooth wear In: Addy M, Embery G, Edger WM, and Orchadson R. Tooth wear and sensitivity. Martin Dunitz, London: 93-104.

8. Watson IB, Tulloch EN (1985) Clinical assessment of cases of tooth surface loss. Br Dent J 159: 144-148.

9. Addy M, Shellis RP (2006) Interaction between attrition, abrasion and erosion in tooth wear. Monogr Oral Sci 20: 17-31.

10. Milosevic A, Lo MS (1996) Tooth wear in three ethnic groups in Sabah (northern Borneo). Int Dent J 46: 572-578.

11. Oginni $O$, Olusile $A O(2002)$ The prevalence, aetiology and clinical appearance of tooth wear: the Nigerian experience. Int Dent J 52: 268-272.

12. Rafeek RN, Marchan S, Eder A, Smith WA (2006) Tooth surface loss in adult subjects attending a university dental clinic in Trinidad. Int Dent J 56: 181-186.

13. Van Rijkom HM, Truin GJ, Frencken JE, König KG, van 't Hof MA, et al. (2002) Prevalence, distribution and background variables of smooth-bordered tooth wear in teenagers in the hague, the Netherlands. Caries Res 36: 147-154.

14. Jaeggi T, Lussi A (2006) Prevalence, incidence and distribution of erosion. Monogr Oral Sci 20: 44-65.
15. Markowitz K, Pashley DH (2007) Personal reflections on a sensitive subject. J Dent Res 86: 292-295.

16. Addy M (2000) Dentine hypersensitivity: definition, prevalence, distribution and aetiology. In: Tooth wear and sensitivity: clinical advances in restorative dentistry, Addy M, Embery G, Edgar WM, Orchardson R eds, Martin Dunitz, London, 239-248.

17. Porto IC, Andrade AK, Montes MA (2009) Diagnosis and treatment of dentinal hypersensitivity. J Oral Sci 51: 323-332.

18. Bishop K, Briggs P, Kelleher M (1994) Theaetiology and management of localized anterior tooth wear in the young adult. Dent Update 21: 153-160.

19. Christensen GJ (2000) Treating bruxism and clenching. J Am Dent Assoc 131: 233-235.

20. Rani M, Bonu S, Jha P, Nguyen SN, Jamjoum L (2003) Tobacco use in India: prevalence and predictors of smoking and chewing in a national cross sectional household survey. Tob Control 12: e4.

21. Gupta PC (1996) Survey of sociodemographic characteristics of tobacco use among 99,598 individuals in Bombay, India using handheld computers. Tob Control 5: 114-120.

22. Nagarajappa R, Ramesh G (2012) Tooth wear among tobacco chewers in the rural population of Davangere, India. Oral Health Prev Dent 10: 107-112.

23. Maharashtra among top tobacco consumers in India Friday, Jun 15, 2012, 19:44 IST | Place: Mumbai | Agency: IA 